\title{
Autoimmune Cytopenia
}

National Cancer Institute

\section{Source}

National Cancer Institute. Autoimmune Cytopenia. NCI Thesaurus. Code C99382.

Cytopenia caused by autoantibodies against the red blood cells, neutrophils, and/or platelets. 